\title{
A new method for dating the surface exposure age of granite rock walls in the Mont Blanc massif by reflectance spectroscopy
}

\author{
Xavi Gallach a,b, Yves Perrette a, Dominique Lafon c, Emilie Chalmin a, Philip Deline a, Ludovic Ravanel a, Julien Carcaillet ${ }^{b}$, \\ Tanguy Wallet ${ }^{a}$ \\ a Univ. Savoie Mont Blanc, CNRS, EDYTEM, 73000, Chambéry, France xavi.gallach.geo@gmail.com \\ b Univ. Grenoble Alpes, Univ. Savoie Mont Blanc, CNRS, IRD, IFSTTAR, ISTerre, 38000, Grenoble, France \\ c IMT Mines Alès. Alès, France
}

Keywords: Cosmogenic nuclide, Exposure dating, Beryllium-10, Reflectance spectroscopy, Granite, Rockfall, Mont Blanc massif

Abstract :

In the high mountain rock walls of the Mont Blanc massif, changes in the granite surface colour are related to its exposure age. The light grey colour of fresh rock surfaces turns orange when is long exposed to weathering. In order to study this colour/age relationship, reflectance spectroscopy was performed on 73 samples, and Terrestrial Cosmogenic Nuclide (TCN) dating was used to obtain their surface exposure age. The standard deviation of the reflectance values was calculated for each wavelength of the visible spectrum to study the behaviour of each spectral region. The aim was to find two colour regions that showed opposite behaviour, and once they are combined, they could provide a representative index of the rock colour changes that are linked to the degree of weathering. As an adaptation of the Green Red Vegetation Index used to measure colour changes in vegetation, the GReen- Infrared GRanite Index (GRIGRI), a normalized difference between the granite $770 \mathrm{~nm}$ and $530 \mathrm{~nm}$ reflectance values, was developed. The GRIGRI value of a weathered granite surface has a close relationship with its exposure age $(R 2=0.85)$. The reflectance spectra of seven samples for which TCN dating failed and two samples for which the TCN age was considered to be an outlier were used to calculate their GRIGRI value to assess the colour-based ages, that were plausible according to rock wall morphology and the TCN exposure ages of the surrounding surfaces. We propose a new method of surface dating for the rock walls of the Mont Blanc massif using reflectance spectroscopy.

\section{Introduction}

In the Mont Blanc massif (MBM), rockfalls and rock avalanches are recurrent hazards for infrastructure and alpinists. Rockfalls since the Little Ice Age (LIA) have been studied by comparison of historical photographs (Ravanel and Deline, 2008, 2010), while current rockfalls are surveyed since 2007 by a network of observers (Ravanel et al., 2010; Ravanel and Deline, 2013). An increase in rockfall frequency in the massif over the last 30 years is correlated to the permafrost degradation caused by the current air warming. In order to understand this relationship over a longer timescale, Terrestrial Cosmogenic Nuclide (TCN) surface exposure dating has been used to date a selection of paleo-rockfalls in the Glacier du Geant basin rock walls (Bohlert et al., 2008; Gallach et al., 2018, 2020). Most of the resulting ages have been correlated to some warm periods of the Holocene (Gallach et al., 2020).

TCN dating is considered to be the most precise method available for surface exposure dating, however its complexity and expensiveness can become a limitation, and they sometimes preclude obtaining large statistically robust datasets. In addition, sample preparation is a long process, and it uses several chemical products (Kohl and Nishiizumi, 1992; Ivy-Ochs, 1996; Merchel and Herpers, 1999) that are toxic and polluting. Complementary to TCN, some faster and less expensive methods such as weathering rind measurements (Chinn, 1981) and Schmidt-hammer dating (SHD; e.g., Shakesby et al., 2006) have been developed for surface exposure dating. Although they do not provide similar precision when dating individual events, calibration of a few samples against an independent absolute dating method (mostly radiometric) results in a calibration curve that can be used for date large datasets (e.g., Chinn, 1981; Gellatly, 1984; Laustela et al., 2003; Gordon and Dorn, 2005; Tomkins et al., 2016; 2018a; 2018b; Matthews et al., 2018), helping to improve statistics when reconstructing the history of natural phenomena.

The use of a quick method in the MBM could multiply the number of rockfall ages, improving the detection of high rockfall occurrence periods occurred during the Holocene and pre-Holocene epochs. The near- vertical slope of the MBM rock walls and the absence of rockfall debris at their base prevents the generalised use of methods such as weathering rind measurements or SHD. Finding another simple and inexpensive method to date rockfalls is crucial in order to perform a dating campaign at the scale of the whole MBM massif.

Amongst the characteristics of any geomaterial (e.g., rock, soil, sediment), the colour is one of the most changing due to weathering elements (e.g., water, chemical elements, microbiota). Because weathering is time-dependent, colour could be a proxy of the duration of weathering. For instance, the intensity of the red colour resulting from oxidation of ferromagnesian minerals in a soil is an indicator of its pedogenetic stage. Reflectance spectroscopy (Shields et al., 1968) and spectrophotometry (Torrent et al., 1984) have shown that soil redness is closely linked to the presence of hematite in the parent rock. The colour gradient is currently used as part of the profile development index of a soil because it is a proxy of the soil age (Harden, 1982; Goodman et al., 2001).

A similar pattern can be established on parent rocks containing ferromagnesian minerals. Changes in the colour of weathered granodiorite surfaces have been observed, with the fresh rock colour becoming brownish with weathering (Saito et al., 1971). Oxidation of granite creates a colour aureole around biotite (Matsuo and Sawa, 1972). Performing diffuse reflectance spectroscopy on powdered granites, Nagano and Nakashima (1989) showed that the degree of a weathering process can be characterised by studying the colour changes.

In the MBM, colour change between fresh and long-exposed granite surfaces is highlighted by each rockfall as follows: light grey colour of a recent rockfall scar corresponds to non-weathered granite, whereas the surface of long-exposed rock walls has a typical orange-reddish colour, as shown, for example, by the west face of the Drus (Ravanel and Deline, 2008). Redness of the granite rock surfaces in the MBM was preliminarily shown to be time-dependent by Bohlert et al. (2008), and was used as a proxy of relative exposure age for TCN dating sampling (Gallach et al., 2018, 2020).

Evolution of the MBM granite redness was first studied by analysing five rock samples that were extracted from the Aiguille du Midi during a pilot campaign (Bohlert et al., 2008). Laboratory reflectance spectroscopy, allowing quantification of the colour of a given surface, was performed to characterise the colour of 
the samples surfaces, and their absolute exposure ages were obtained using Beryllium-10 $\left({ }^{10} \mathrm{Be}\right) \mathrm{TCN}$ dating. The continuum-removed spectra of the five samples were successfully correlated to their exposure ages.

In order to verify the relationship between the rock surface colour and its exposure age, a larger study has been performed. When using the continuum-removed spectra and TCN ages of the whole dataset, the colour/age relationship shows some inconsistencies. In this study, we used different approaches to explore the colour/age relationship and the colour changes of the MBM granite surfaces, with the aim to estimate the exposure ages using only reflectance spectroscopy.

\section{The Mont Blanc granite}

The MBM is a crystalline massif that extends over $550 \mathrm{~km}^{2}$ in the Western European Alps; a large area is higher than $3000 \mathrm{~m}$ above sea level (a.s.l.), with many crests and peaks reaching $4000 \mathrm{~m}$ a.s.l. It is composed of two main lithological units: a Hercynian metamorphic series on its west (W) and northwest (NW) margins, and an intrusive late- Hercynian granite in its central and eastern (E) parts. Hercynian and Alpine orogenesis created two main northwest-southeast (NW-SE) and northeast-southwest (NE-SW) fracture sets, respectively (Bertini et al., 1985; Gallach et al., 2020). The high-elevated central part of the MBM, which is characterised by its dense fracturation and by the steepness of its rock walls, is very conducive to rockfalls (Deline et al., 2012). 27\% of its surface area is covered by glaciers (Gardent et al., 2014), and continuous permafrost is present in at least $40 \mathrm{~km}^{2}$ of rock walls that are steeper than $40^{\circ}$ (Magnin et al., 2015).

The granite of the Glacier du Géant basin is the 'central facies granite', which is present in most of the MBM (Bussy, 1990) and characterised by its homogeneous composition (Rossi, 2005). It contains c. 5\% of biotite, its main ferromagnesian mineral (Bussy, 1990). Because the microdesquamation of granite and subsequent formation of grus and/or soil is extremely difficult in cold and dry environments, chemical erosion in the Glacier du G'eant basin can be considered to be nonexistent. However, chemical weathering of the ferrous iron $\left(\mathrm{Fe}^{2+}\right)$ contained in the biotite of granitic surfaces produces soluble ferric iron $\left(\mathrm{Fe}^{3+}\right)$ oxides, i.e. goethite $\alpha-\mathrm{FeO}(\mathrm{OH})$ and hematite $\mathrm{Fe}_{2} \mathrm{O}_{3}$ (Nakashima and Nagano, 1989). Precipitation of goethite and hematite in the granite surfaces can create an iron film (Dorn, 1998), and a weathering rind on most weathered surfaces (e.g., Gellatly, 1984; Kanamaru et al., 2018). In the MBM, this results in the typical orange-reddish colour of its rock walls (Gallach et al., 2018).

X-ray fluorescence spectrometry with an energy dispersive SPECTRO X-LAB 2000 (SPECTRO Analytical Instruments) was conducted on five samples of the pilot study (Bohlert et al., 2008), and this method showed a homogeneous rock composition, which means that colour changes in the rock surface are not due to differences in chemical composition.

\section{Rock wall surface exposure dating}

\subsection{Sampling}

All rock samples (Fig. 1; Table 1) have been extracted from nine rock walls that are located in the central part of the MBM at elevations ranging from 3200 to $3800 \mathrm{~m}$ a.s.l. and exposed $\mathrm{E}$ and $\mathrm{SE}$, where the transition from grey to orange/red colour is the most evident. The northernmost (Aiguille du Midi) and southernmost (Tour Ronde, on the crest line between France and Italy) sites are $4.2 \mathrm{~km}$ apart.

Colour contrast was applied using Adobe $@$ Photoshop to high resolution photographs of the nine sites, to better determine the rock surfaces that were to be sampled (Gallach et al., 2020). In order to prevent potential ${ }^{10} \mathrm{Be}$ produced in the sampled surfaces before the rock slope failure (inheritance), sampling was performed on rockfall scars with a depth of $>3 \mathrm{~m}$. At the sampling scale, only areas where the surface colour was representative of the average colour of the given rock wall surface were selected. Sampling was performed by abseiling down each rock wall from its summit, which was accessed either by cable-car or helicopter, and by cutting a rectangular piece of rock with an angle grinder or a percussion drill. All samples were extracted from slopes in the range $42-90^{\circ}$ (mean: $76^{\circ}$ ), and far from shear zones and ledges in order to prevent snow accumulation that could accelerate rock weathering. Collected samples were 3-8 $\mathrm{cm}$ thick, had a surface $>100 \mathrm{~cm}^{2}$, and weighted 1-3 kg. Most of the sample mass was used for TCN dating of rockfall scars; a section with a surface measuring $>50$ $\mathrm{cm}^{2}$ was reserved for reflectance spectroscopy.

Three sampling campaigns were conducted in 2006, 2011, and 2015-2016. A total of 81 samples, including six replicates and one sample of fresh rock, were extracted at nine different sites in the Glacier du Géant basin (Gallach et al., 2018, 2020).

\subsection{Terrestrial cosmogenic nuclide dating}

Surface exposure ages were calculated using ${ }^{10} \mathrm{Be}$ TCN dating. The 25 samples from the 2006 and 2011 campaigns were processed at the University of Zurich (Switzerland; Bohlert et al., 2008; Gallach et al., 2018). The ${ }^{10} \mathrm{Be} /{ }^{9} \mathrm{Be}$ ratios were measured at the ETH Zurich Tandem Accelerator Mass Spectrometry (AMS) facility (Zurich, Switzerland; Kubik and Christl, 2010). The 55 samples from the 2015-2016 campaign were processed at the ISTerre GeoThermoChronology platform (Grenoble, France; Gallach et al., 2020). The ${ }^{10} \mathrm{Be} /{ }^{9}$ Be ratios were measured at the ASTER-CEREGE Accelerator Mass Spectrometry (AMS) facility (Aix-en-Provence, France; Arnold et al., 2010).

The ages were computed using the CRONUS-Earth Web Calculators version 2.0 (http://cronus.cosmogenicnuclides.rocks/2.0/; Marrero et al., 2016). Surface exposure ages of the 2006 and 2011 campaigns were re-calculated in 2018 using the same parameters, in order to obtain a homogeneous data set (Table 1; Gallach et al., 2020).

Snow accumulation was absent, and surface erosion was insignificant because of the low air temperature and fluid percolation, both unfavourable for frost shattering. Therefore, no correction for snow or for erosion was applied. Potential inheritance at a depth of $3 \mathrm{~m}$ was estimated, showing low values ( $\leq 2 \%)$ in most cases, and all the ${ }^{10} \mathrm{Be}$ concentrations were corrected. Exposure ages were considered as the minima for the last rockfalls.

62 samples were successfully dated, with exposure ages ranging from $0.03 \pm 0.02$ to $88.40 \pm 7.60 \mathrm{ka}$.

\section{Laboratory reflectance spectroscopy}

Reflectance spectroscopy is a remote sensing method that consists of quantifying the amount of natural or artificial light that is reflected by any material surface (Clark, 1999). It can be performed by laboratory or outdoor spectrometers on a variety of wavelengths in the ultraviolet (UV; 1-400 $\mathrm{nm}$ ), visible ( 400-700 $\mathrm{nm}$ ), 
near-infrared (NIR; 700-3000 nm), mid-infrared (MIR; 3-30 $\mu \mathrm{m}$ ), and far infrared (FIR; 30 $\mu \mathrm{m}-1 \mathrm{~mm}$ ) portions of the electromagnetic spectrum. Laboratory reflectance spectra are obtained in a controlled environment and are usually corrected according to a blank (the reflectance spectrum resulting from projecting the same artificial light that was used for the study towards a standard white surface).

Laboratory reflectance spectroscopy was conducted on each sample to quantify the rock surface colour. Reflectance spectra of samples that were collected in 2006 and 2011 (Bohlert et al., 2008; Gallach et al., 2018) were measured at the University of Zurich (Switzerland) using an Analytical Spectral Devices (ASD) FieldSpec ${ }^{\otimes} 3$ portable spectro-radiometer covering the range $350-2500 \mathrm{~nm}$ (3-nm resolution at $700 \mathrm{~nm}$, sampling interval: $1.4 \mathrm{~nm}$ at $350-1050 \mathrm{~nm}$ ), a Spectralon white reference panel, and a 3200K Dedolight DLH4 (DLH-4) universal 12/24v tungsten lamp head with Aspherics 2 light source. Each sample was placed onto a flat surface. The contact probe and the light source were placed $20 \mathrm{~cm}$ directly above the sample to obtain a disk of $c$. $90 \mathrm{~mm}$ in diameter as a measurement area. Four reflectance spectra were obtained for each sample, turning it $90^{\circ}$ between each measurement, and averaged.

Reflectance spectra of the samples that were collected in 2015-2016 (Gallach et al., 2020) were measured at the IMT Mines Ales laboratory (Alès, France), using a Konica Minolta CS-2000 spectro-radiometer covering the range 380-780 nm (1-nm resolution, sampling interval: $1 \mathrm{~nm}$ ), a Barium sulphate (BaSO $\left.{ }_{4}\right)$ white reference, and a $4700 \mathrm{~K}$ light source that provide good D50 light stimulation (Colour Rendering Index of the light source: 99.35) with a smooth, continuous, and full spectral power distribution. Each sample was exposed on a vertical flat surface normal to the measuring direction. To measure the diffuse reflection and avoid specular reflection on mineral surfaces, lighting conditions were fixed such that the surface did not shine and was uniformly lighted. The spectrometer and the light source were placed $3.40 \mathrm{~m}$ from the sample in order to obtain a disk c. $48 \mathrm{~mm}$ in diameter as a measurement area, which was large enough to measure the rock colouration rather than the grain colourations. Two reflectance spectra were obtained for each sample, turning it $90^{\circ}$ between each measurement, and averaged.

In both campaigns, reflectance spectra were acquired in a dark room with a black background to avoid secondary reflection. To increase the signal/noise (S/N) ratio, especially for the shorter wavelengths that are characterised by low excitation and detection, all spectra were smoothed performing an 11-nm windowcentred moving average. Although the two datasets were acquired using different experimental setups, the expected difference may be linked to the use of two white references (Spectralon versus $\mathrm{BaSO}_{4}$ ), which are commonly used in spectrophotometry either in the laboratory or in the field for the Spectralon reference. Based on different reflectance spectra found in literature, white reference changes account for only $2 \%$ of the different ratio used. For this study, we ignored this difference and merged both of the datasets.

\subsection{Colour-age relationship based on continuum-removed spectra}

Colour changes on the MBM granite surface were first studied by Bohlert et al. (2008) using four long-exposed rock samples and a fresh sample. To compare spectra with different characteristics, reflectance spectra of the sample surfaces were normalised as continuum-removed spectra (Green and Craig, 1985) by creating a convex hull of every spectrum, and dividing the reflectance values of the spectrum by the values of the resulting convex hull. This results in a normalised spectrum with reflectance values in the range $0-1$.

The results showed a good correlation between the continuum- removed spectra and their TCN exposure ages, as follows: while fresh rock with the youngest exposure age show normalised reflectance values near 1 , spectra of the three oldest samples decreased towards lower values, according to their increasing exposure age.

Further analysis with a larger dataset was requested to verify these preliminary results. 73 reflectance spectra were available out of a total of 81 samples; 8 samples were not included in the analysis, which corresponded to: 6 samples were TCN replicates of samples ADM1, ADM12 and ECO7; sample ADM3 was covered by lichen (Bohlert et al., 2008); and sample LA3 was lost. Continuum-removed spectra analysis has been performed using only samples of both known exposure age and verified reflectance spectra. 15 of the 73 spectra were not included, which corresponded to: 9 samples (ADM6, ADM7, ADM10, CHD7, ECO1, PYR1, TRI3, TRO3, TRO9) without a TCN age, three TCN ages (ADR7, PYR5, TRI2) that were considered to be outliers (Gallach et al., 2020), and three samples $(E C O 6, E C O 7, E C O 8)$ that were collected from a surface in the lower part of the Cosmiques spur and that showed an anomalous brown colour that was interpreted to be the result of iron oxide that precipitated inside the fracture before the rockfall; it, therefore, showed a colour that was considered to be an outlier.

The final dataset of 58 spectra (Fig. 2) confirms the pattern from the pilot study, with feature absorption values decreasing in the 380-600 $\mathrm{nm}$ region. The general shape of the dataset allows detection of three Gaussian-like absorption regions, which correspond to three patterns, with the maximal absorption at 380-450 $\mathrm{nm}, 450-600 \mathrm{~nm}$, and 600-780 nm.

There is a first-order relationship between the exposure age of the samples and the depth of the absorption regions in their continuum- removed spectra: younger ages are closer to 1 while older ages show lower values. Continuum-removed spectra are well-designed to detect the degree of weathering of a granite surface. However, a more detailed analysis of this large dataset revealed some inconsistencies, especially in the 450-590 nm absorption band, as follows (Fig. 2): i) some spectra cross each other, making it difficult to estimate their relative absorption pattern; ii) some spectra (especially for younger samples) show the band minimum at around $420 \mathrm{~nm}$, while others are at around $480 \mathrm{~nm}$, which makes it difficult to choose a specific wavelength as a representative value for the degree of weathering; iii) three spectra for ages $>10$ ka showed a higher band depth than several spectra that corresponded to younger ages; iv) several spectra for ages 1-5 ka showed similar or lower reflectance than spectra that corresponded to the exposure ages 5-10 ka.

Thus, a method that is based on the continuum-removal filtering is not robust enough to date rock walls because of the dissimilarities between initial colours. The convex hull fitted on the top of the reflectance spectrum is sensitive to the general colour and can induce changes that are not associated with weathering but, rather, to initial colours.

\subsection{Colour-age relationship based on CIE $1931 x, y$ coordinates}

The CIE $1931 x, y$ colour space is a theoretical colour representation that allows the information contained in a visible spectrum to be reduced into two values or coordinates (Ohno, 2000). The resulting $\mathrm{x}, \mathrm{y}$ coordinates are issued based on the XYZ tristimulus values, which correspond to the three regions that are visible to the human eye. The CIE 1931 chromaticity diagram allows the visual representation of a given colour.

Conversion of the precedent 58 reflectance spectra to CIE $1931 \mathrm{x}, \mathrm{y}$ coordinates resulted in a cluster of dots (Fig. 3). The x,y values form a continuous path, from c. $0.32,0.34$ (corresponding to sample TRO5; $0.12 \pm 0.03 \mathrm{ka}$ ) to $c$. $0.4,0.375$ (corresponding to the oldest age of the cluster: ADR6, $88.40 \pm 7.60 \mathrm{ka}$ ). These values corresponded to the white and orange colour regions, respectively, which are represented in the chromaticity diagram CIE 1931 . Although a progressive change in the values that correspond to the rock surface colour is consistent with their growing exposure age, numerous inconsistences prevent the establishment of a 
continuous colour/age relationship based on the use of CIE 1931 x,y coordinates (Fig. 3). The cluster is not a straight line, which may be because the aging phenomena caused a change in the surface composition.

\subsection{Exploring a vegetation index-like method}

Vegetation Indices (VI) are commonly based on the ratio between the reflectance values of two channels of an aerial or satellite multispectral image. VIs are used in remote sensing as an effective tool to map vegetation cover and monitor phenological changes (Tucker, 1978).

Most VIs are based on simple or normalised ratios between Red $(\sim 620-700 \mathrm{~nm})$ and NIr $(\sim 700-1100 \mathrm{~nm})$ bands on multispectral images. The Normalised Difference Vegetation Index (NDVI; [NIr - Red]/ [NIr + Red]) is widely used in vegetation mapping because living plants absorb radiation in the Photosynthetically Active Region $(400-700 \mathrm{~nm}$ ) and reflect at wavelengths $>700 \mathrm{~nm}$. Although NDVI is used in many phenological studies when mapping or studying specific species or processes, it presents some problems (e.g., to monitor leaf falling). To solve these problems, many indices have been developed to use remote sensing for any specific quest (Vescovo et al., 2012).

We evaluated several indices and developed an index that was based on the Green Red Vegetation Index (GRVI). The GRVI is an evolution of the NDVI that uses the ratio between Green ( $\sim 50-570 \mathrm{~nm}$ ) and Red ( $620-700 \mathrm{~nm}$ ) reflectance of plants ([Green - Red]/[Green + Red]; Tucker, 1978), which is very efficient for measuring colour changes in vegetation (Falkowski et al., 2005; Motohka et al., 2010).

The first step was to reduce and select the spectral bands to use as age predictors to increase the optimisation of the model and to make it more robust. Colour spectra are known to be characterised by interband broad covariations. To increase the $\mathrm{S} / \mathrm{N}$ ratio and to reduce the number of bands to be tested, spectra were resampled linearly at a $10-\mathrm{nm}$ step. Because of the low $\mathrm{S} / \mathrm{N}$ ratio, the Violet band $(<450 \mathrm{~nm})$ was not considered. The most informative bands were selected on the basis of the variability between spectra (Fig. 4), using the standard deviation (in the dimension of samples with the raw spectra, left axis) and correlation with the target log age (right axis). Wavelengths are chosen in order to combine a wavelength that is highly informative and well correlated with a wavelength that has low variability and a low correlation that is used for index normalisation. The Green band ( $520-560 \mathrm{~nm})$, with a maximum SD at $530 \mathrm{~nm}$ was selected along with a Red/Infrared band ( $>590 \mathrm{~nm}$ ), with a minimum SD at $770 \mathrm{~nm}$. The results confirm that, when considering weathered and non-weathered rock, the main changes are in the Green band, while reflectance changes in the Red and Near- Infrared band are less significant. As shown in Fig. 2 and in Table 1, old samples show lower reflectance values in the Green region compared to the young samples, confirming that the weathering-induced redness of the granite surface corresponds to an increase of Green absorption rather than an increase of Red reflectance.

To test the importance of considering other colours of the visible spectra, Blue $(450 \mathrm{~nm})$ and Red $(700 \mathrm{~nm})$ wavelengths were also selected, providing four possible combinations: Blue/Red, Blue/Infrared, Green/Red and Green/Infrared.

As in the GRVI formula, the following formula was used to reduce the weight of the reflectance value:

Granite Index: $(A-B) /(A+B)$

where $A$ is the long $(700 \mathrm{~nm}, 770 \mathrm{~nm})$ and $B$ is the short $(450 \mathrm{~nm}, 530 \mathrm{~nm})$ wavelength reflectance value. This index increases with the decrease in the low wavelength reflectance, in a manner that is similar to the supposed exposure age. Their combinations lead to the following four granite indices (unit: $\mathrm{nm}$ ):

Blue/Red Index: $(700-450) /(700+450)$ :

Blue/Infrared Index: $(770-450) /(770+450)$;

Green/Red Index: $(700-530) /(700+530)$;

Green/Infrared Index: $(770-530) /(770+530)$.

\section{Results}

\subsection{The GReen infrared GRanite index (GRIGRI)}

From the 58 samples that were used in the previous steps (section 4.1), four very young samples (ADMf, fresh rock; COS1, $0.03 \pm 0.02 \mathrm{ka}$; ADR3, $0.04 \pm 0.01 \mathrm{ka}$; and ADR5, age $<0.23 \pm 0.09$ ka due to analytical problems; Gallach et al., 2020) did not show any weathering and were considered too young for the analysis. The four granite indices were calculated for the remaining 54 samples and correlated with the surface exposure ages. Because colour changes in a non-linear way, surface exposure ages (ka) were converted to the natural logarithm (log ka; Table 1).

The first analysis resulted in a good correlation of $R^{2} \geq 0.66$ for the four granite indices, but the best correlated index was the ratio between Green and Infrared reflectance values $\left(R^{2}=0.72, n=54\right)$. This is in agreement with the standard deviations and the correlation values that are shown in Fig. 4 : the higher standard deviation and anti-correlation are in the green band, while the lower standard deviation and anti- correlation are in the infrared band, which optimised the prediction. To consider the potential bias in exposure age determination and colour estimation, a robust statistic method led to exclusion of four outliers based on their Cook's distance (ECO2, PYR2, TRI7, TRI9), and this resulted in a robust correlation $\left(R^{2}=0.85, n=50 ;\right.$ Fig. 5). Modelling hereafter uses this robust dataset of 50 samples.

To characterise the weathering of the MBM high altitude granite, we propose the following GReen Infrared GRanite Index (GRIGRI; Table 1):

GRIGRI = (R770 nm - R530 nm) / (R770 nm + R530 nm) where $R$ is reflectance of the corresponding wavelength. The linear model (Fig. 6) was calculated using a Monte Carlo procedure to propagate age uncertainty in the Gaussian distribution for age uncertainty. The convergence was checked with the main model parameters (slope, $\mathrm{Y}$ intercept, and $\mathrm{R}^{2}$ ). This model was steady and a convergence was reached in less than 100 iterations. A Bootstrap cross-validation using a $2 / 3-$ to- $1 / 3$ ratio of training vs. validation set was then used to estimate the uncertainty of the linear model (confidence interval, prediction interval, and root mean square error).

Partial least squares (PLS) regression for the chemometric procedure (Wold et al., 1984) was also tested, but the prediction increase was low $\left(R^{2}=0.81\right)$. Following a parsimony view, hereafter, we use and discuss the simple GRIGRI linear model. 


\subsection{Using the GRIGRI where TCN dating failed or was an outlier}

Nine samples had an unknown exposure age because TCN dating failed or their exposure age was considered to be an outlier. Because their reflectance values were available, they were used as the first dataset for GRIGRI exposure dating (Table 2).

Seven of eight samples for which TCN dating failed were used, and ECO1 was excluded because of its exceptionally dark colour, which was presumably due to iron precipitation (metasomatism) in the fractures before the rockfall. Three samples (ADR7, PYR5, TRI2) had a TCN age that was considered to be an outlier (Gallach et al., 2020). Among these, TRI2 was not used for the test because it presented a strong surface desquamation; neither its surface nor its colour directly resulted from the rockfall that exposed the scar.

GRIGRI ages obtained for these nine samples were consistent with the TCN ages and the geomorphology of the surrounding sampling sites (Fig. 7).

\section{Discussion and outlook}

\subsection{Exposure age modelling considerations}

The simplest model presented here allows prediction of the log of exposure ages using a simple colour index. However, scar orientation, slope and elevation are parameters that could be considered to be important for MBM rock weathering. Furthermore, a single log-linear approach assumes a continuous colour change during weathering, which does not make sense at the short and long time scales.

During sampling, the bias induced by snow cover was greatly reduced by avoiding cliff ledges. Aspect and elevation weight were explored using multilinear modelling and analysis of prediction error (residuals). PLS or simple multilinear modelling were attempted many times. Modelling was never better than those that were estimated using a single parameter. Independency of topographical parameters and model ages could be explained by the predominance of atmospheric exposure (oxidation). Such an interpretation negates the potential role of biotic control on granite weathering, which may be sensitive to environmental parameters, as demonstrated by many studies (e.g., Etienne, 2002; Wang et al., 2011). To test this assumption, we divided the dataset to produce south and north subsets upon which the model could be discussed. However, because of the present distribution of ages and aspects (Fig. 1) in the whole dataset, this work was not possible using either PLS or multilinear modelling. A more reliable analysis was conducted on the prediction error (signed residual between predicted to empirical age), and no correlation or specific pattern was obtained. According to our present knowledge and the dataset, surface exposure age is the main factor that controls the surface redness that is linked to granite weathering.

The continuity of weathering with the log of time was tested using the Monte Carlo and Bootstrap method to model the log of age/colour index relationship for ages that were less than 1,10, or $100 \mathrm{ka}$ (the whole dataset). For each subset, modelling converges with good confidence. In a more detailed analysis, we observed that the model quality increased with the age range. This could be artificially linked to the few samples with an old age, which had higher inertia in the model. A short test using the population of each subset (by random standardisation of the effectiveness in the lower subset) did not change this result. However, coupling this uncertainty with an increase in the 'slope' of the relationship seems to show that, as suspected, the weathering may not be continuous with the log of age. Indeed, the weathering process is expected to take some time to begin (hundreds of years), and then a period of continuous weathering exists (few kyr), followed by a period that shows a progressive decrease (tens of kyr, when the steady colour is approached). For example, a logit model for weathering could be introduced in the model in order to consider the change of weathering intensity over time. This was briefly tested but without a clear improvement because of the age uncertainty and the limited number of samples. As a perspective, a logit-based model may increase the ability to better predict young and old ages. 6.2 . Application of the GRIGRI in the MBM

The GRIGRI allows estimation of the exposure age of central MBM granite rock surfaces. However, there is an apparent loss of precision for exposure ages that are older than $10 \mathrm{ka}$. This can be explained by the growing absolute uncertainty of the TCN ages (e.g., $7.60 \mathrm{ka}$ for ADR6, which has an age of $88.40 \mathrm{ka}$ ), whereas reflectance spectra show that the colour of samples with a multi-millennial age is approaching the steady state (the older the exposure age of a granite surface, the less its colour variation). Since TCN ages that are older than $10 \mathrm{ka}$ show uncertainties $>1 \mathrm{ka}$ (Table 1), these ages are not suitable for direct correlation with climate periods (e.g., Last Glacial interstadials; Gallach et al., 2020). The GRIGRI becomes less relevant for dating pre-Holocene exposed rock wall surfaces, but because it does not intend to overcome the precision of other exposure age dating methods, this fact does not become a serious barrier.

\subsection{Exploring the use of other remote sensing techniques}

Laboratory reflectance spectroscopy is the most reliable method to characterise rock surface colours (Nagano and Nakashima, 1989; Clark, 1999; Sgavetti et al., 2006; Bohlert et al., 2008). However, mandatory sampling in rock walls is constraining (e.g., helicopter approach, abseiling down the rock walls). A simpler, faster, and safer method to obtain reflectance spectra of the rock surfaces would allow reflectance spectroscopy studies for the rock walls of a whole massif. The main problem with collecting reflectance data in situ is light calibration, especially because the high albedo of the glacier accumulation zone at the base of rock walls saturates the light. Although light calibration for cartographic orthogonal remote sensing images (e.g., satellite imaging, aerial photographs) has been resolved (e.g., Roujean et al., 1992), short and medium-range spectroscopic techniques (ground or airborne based spectrometers) need to deal with real-time light calibration for each acquisition point.

The use of photographic techniques could simplify data acquisition. However, RGB values introduce a bias because they are based on the human perception of colours, which does not necessarily correspond to the colour regions where the rock surface shows different dynamics. This limitation can partly be overcome with the use of a converted full- spectrum (visible + NIr) photographic camera and photographic blocking filters (Verhoeven, 2008).

Although this is a consideration on the GRIGRI application, it may be used in non-calibrated photographs in order to map the relative exposure ages within a rock wall. 


\subsection{Applicability of the GRIGRI}

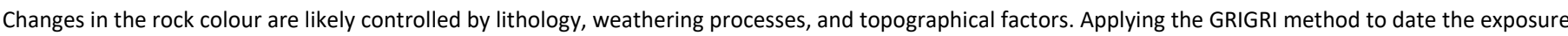

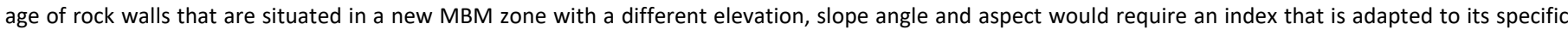
colour dynamics. Calibration of the new index against some absolute dating exposure ages is required.

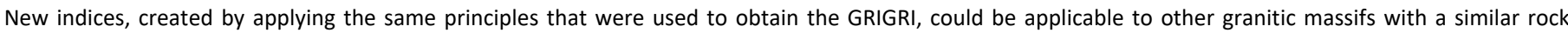

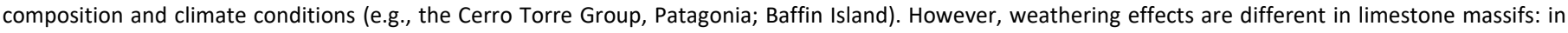

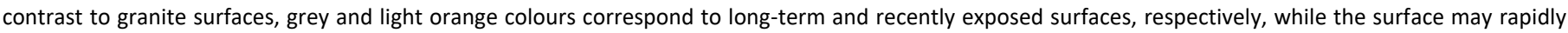
reach a steady colour precluding its use as a proxy for exposure age.

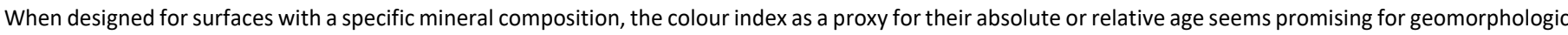
studies.

\section{Conclusion}

The grey colour of the Mont Blanc granite (exposed due to a rockfall) becomes orange when exposed for a long time to subaerial conditions. The rock colour

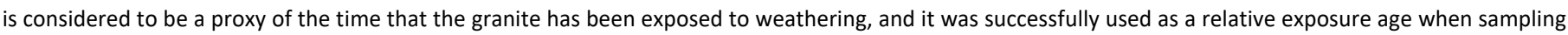

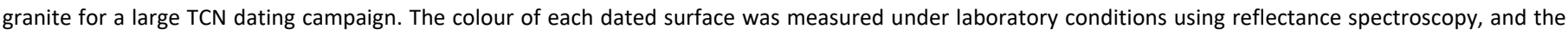
granite colour/age relationship was explored with different methods using the correspondent exposure age. The study led to the following conclusions:

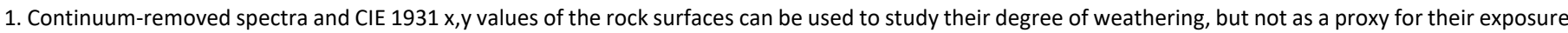
ages.

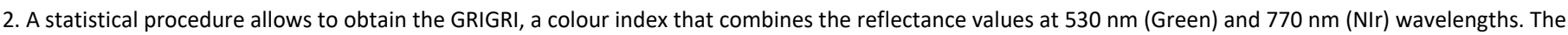

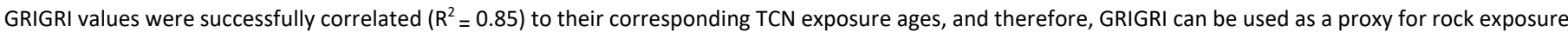
age.

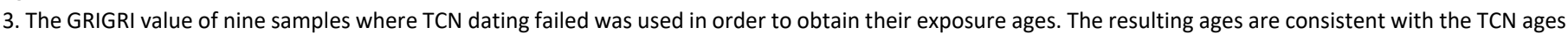

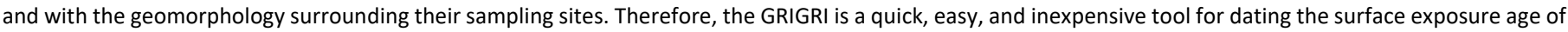
the rock surfaces in the central area of the Mont Blanc massif.

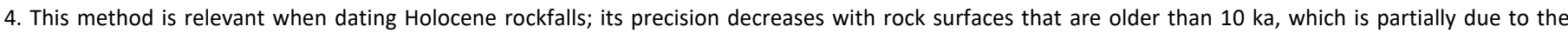
increasing uncertainty of TCN dating.

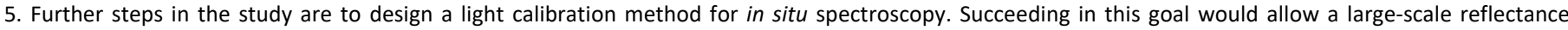

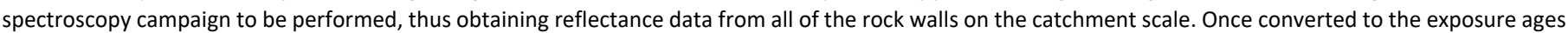

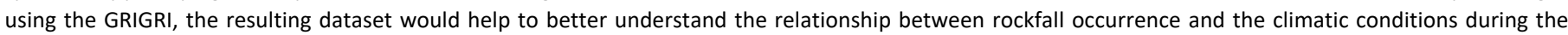
Holocene.

\section{Acknowledgments}

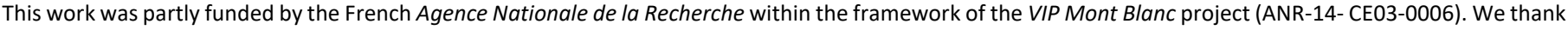

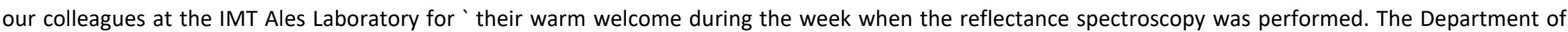

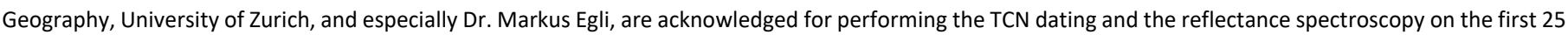

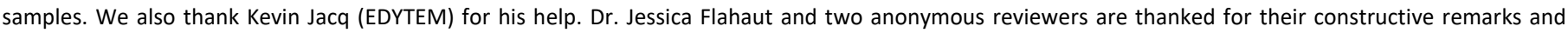
suggestions, which allowed us to improve the quality of the manuscript.

\section{References}

Arnold, M., Merchel, S., Bourles, D.L., Braucher, R., Benedetti, L., Finkel, R.C., Aumaître, G., Gottdang, A., Klein, M., 2010. The French accelerator mass spectrometry facility ASTER: improved performance and developments. Nucl. Instrum. Methods Phys. Res. Sect. B Beam Interact. Mater. Atoms $268,1954-$ 1959. https://doi.org/10.1016/j.nimb.2010.02.107.

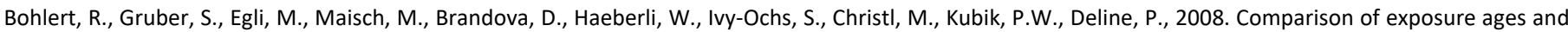

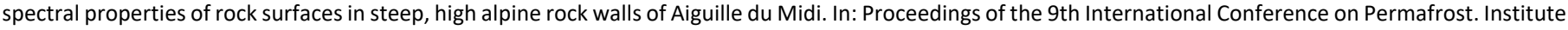
of Northern Engineering - University of Alaska, Fairbanks, pp. 143-148.

Bertini, G., Marcucci, M., Nevini, R., Passerini, P., Sguazzoni, G., 1985. Patterns of faulting in the Mont Blanc granite. Tectonophysics 111 (1-2), 65-106.

Bussy, F., 1990. Pétrogenèse des enclaves microgrenues associées aux granitoïdes calco-alcalins: exemple des massifs varisque du Mont-Blanc (Alpes occidentales) et miocene du Monte Capanne (Ile d’Elbe, Italie). Université de Lausanne.

Chinn, T.J.H., 1981. Use of rock weathering-rind thickness for Holocene absolute age- dating in New Zealand. Arct. Alp. Res. 13 (1), $33-45$.

Clark, R.N., 1999. Spectroscopy of rocks and minerals and principles of spectroscopy: chapter 1. In: Remote Sensing for the Earth Sciences: Manual of Remote Sensing, 3 ed, vol. 3.

Deline, P., Gardent, M., Magnin, F., Ravanel, L., 2012. The morphodynamics of the Mont Blanc massif in a changing cryosphere: a comprehensive review. Geogr. Ann. Phys. Geogr. 94, 265-283. 
Dorn, R.I., 1998. Rock Coatings. Developments in Earth Surface Processes 6. Elsevier, Amsterdam.

Etienne, S., 2002. The role of biological weathering in periglacial areas: a study of weathering rinds in south Iceland. Geomorphology $47,75-86$.

Falkowski, M.J., Gessler, P.E., Morgan, P., Hudak, A.T., Smith, A.M.S., 2005. Characterizing and mapping forest fire fuels using ASTER imagery and gradient modeling. For. Ecol. Manag. 217, 129-146. https://doi.org/10.1016/j.

Gallach, X., Ravanel, L., Egli, M., Brandova, D., Schaepman, M., Christl, M., Gruber, S., Deline, P., Carcaillet, J., Pallandre, F., 2018. Timing of rockfalls in the Mont Blanc massif (Western Alps): evidence from surface exposure dating with cosmogenic 10Be. Landslides 15, 1991-2000. https://doi.org/10.1007/s10346-0180999-8.

Gallach, X., Carcaillet, J., Ravanel, L., Deline, P., Ogier, C., Rossi, M., Malet, E., García- Sellès, D., 2020. Climatic and structural controls on Late-glacial and Holocene rockfall occurrence in high-elevated rock walls of the Mont Blanc massif (Western Alps). Earth Surf. Process. Landforms 45, $3071-3091$. https://doi.org/10.1002/ esp.4952.

Gardent, M., Rabatel, A., Dedieu, J.P., Deline, P., 2014. Multitemporal glacier inventory of the French Alps from the late 1960s to the late 2000s. Global Planet. Change 120, 24-37. https://doi.org/10.1016/j.gloplacha.2014.05.004.

Gellatly, A.F., 1984. The use of rock weathering-rind thickness to redate moraines in Mount Cook National Park, New Zealand. Arct. Alp. Res. 16, 225-232.

Goodman, A.Y., Rodbell, D.T., Seltzer, G.O., Mark, B.G., 2001. Subdivision of glacial deposits in southeastern Peru based on pedogenic development and radiometric ages. Quat. Res. $56(1), 31-50$.

Gordon, S.J., Dorn, R.I., 2005. In situ weathering rind erosion. Geomorphology 67 (1-2), 97-113.

Green, A., Craig, M., 1985. Analysis of Aircraft Spectrometer Data with Logaritmic Residuals (No. N86 11636). NASA.

Harden, J.W., 1982. A quantitative index of soil development from field descriptions: examples from a chronosequence in central California. Geoderma $28,1-28$.

Ivy-Ochs, S., 1996. The Dating of Rock Surfaces Using in Situ Produced 10Be, 26Al and 36Cl, with Examples from Antarctica and the Swiss Alps. PhD Thesis. ETH Zürich, p. 196.

Kanamaru, T., Suganuma, Y., Oiwane, H., Miura, H., Miura, M., Okuno, J.I., Hayakawa, H., 2018. The weathering of granitic rocks in a hyper-arid and hypothermal environment: a case study from the Sør-Rondane Mountains, East Antarctica. Geomorphology 317, 62-74.

Kohl, C.P., Nishiizumi, K., 1992. Chemical isolation of quartz for measurement of in-situ- produced cosmogenic nuclides. Geochem. Cosmochim. Acta 56 (9), $3583-$ 3587.

Kubik, P.W., Christl, M., 2010. 10Be and 26Al measurements at the Zurich 6 MV Tandem AMS facility. Nucl. Instrum. Methods B 268, 880-883.

Laustela, M., Egli, M., Frauenfelder, R., Ka"ab, A., Maisch, M., Haeberli, W., 2003. Weathering rind measurements and relative age dating of rockglacier surfaces in crystalline regions of the Eastern Swiss Alps. In: Permafrost: Proceedings of the Eighth International Conference on Permafrost, pp. $627-632$.

Magnin, F., Brenning, A., Bodin, X., Deline, P., Ravanel, L., 2015. Mod'elisation statistique de la distribution du permafrost de paroi : application au massif du Mont Blanc. G'eomorphol. Relief, Process. Environ. 21, 145-162. https://doi.org/10.4000/ geomorphologie.10965.

Marrero, S.M., Phillips, F.M., Borchers, B., Lifton, N., Aumer, R., Balco, G., 2016. Cosmogenic nuclide systematics and the CRONUScalc program. Quat. Geochronol. 31, 160-187.

Matsuo, S., Sawa, K., 1972. The identification of weathering patterns and their representation methods based on observations of broken surface on decomposed granites. Soils Found. 12, 105-112.

Matthews, J.A., Winkler, S., Wilson, P., Tomkins, M.D., Dortch, J.M., Mourne, R.W., Hill, J.L., Owen, G., Vater, A.E., 2018. Small rock-slope failures conditioned by Holocene permafrost degradation: a new approach and conceptual model based on Schmidt-hammer exposure-age dating, Jotunheimen, southern Norway.

Boreas 47, 1144-1169. https://doi.org/10.1111/bor.12336.

Merchel, S., Herpers, U., 1999. An update on radiochemical separation techniques for the determination of longlived radionuclides via Accelerator Mass Spectrometry. Radiochim. Acta 84, 215-219.

Motohka, T., Nasahara, K.N., Oguma, H., Tsuchida, S., 2010. Applicability of green-red vegetation index for remote sensing of vegetation phenology. Rem. Sens. 2, 2369-2387. https://doi.org/10.3390/rs2102369.

Nagano, T., Nakashima, S., 1989. Study of colors and degrees of weathering of granitic rocks by visible diffuse reflectance spectroscopy. Geochem. J. $23,75-83$. Nakashima, S., Nagano, T., 1989. Long-term reaction path modeling of radionuclide fixation in geosphere by spectroscopic methods. Procedure 1989 Joint waste management conference $2,341-346$. 
Ohno, Y., 2000. CIE fundamentals for color measurements. In: Digital Printing Technologies, IS\&T's NIP16 International Conference. Presented at the International Conference on Digital Printing Tecnologies (Vancouver).

Ravanel, L., Allignol, F., Deline, P., Ravello, M., 2010. Rock falls in the Mont Blanc massif in 2007 and 2008. Landslides 7, 493-501. https://doi.org/10.1007/s10346010- 0206-z.

Ravanel, L., Deline, P., 2008. La face ouest des Drus (massif du Mont-Blanc) : évolution de l'instabilité d'une paroi rocheuse dans la haute montagne alpine depuis la fin du Petit Age Glaciaire. Géomorphol. Relief, Process. Environ. 4, 261-272.

Ravanel, L., Deline, P., 2010. Climate influence on rockfalls in high-Alpine steep rockwalls: the North side of the Aiguilles de Chamonix (Mont Blanc massif) since the end of the Little Ice Age. Holocene 21, 357-365.

Ravanel, L., Deline, P., 2013. A network of observers in the Mont Blanc massif to study rockfalls in high alpine rockwalls. Geogr. Fis. Din. Quaternaria 36, $151-158$. https:// doi.org/10.4461/GFDQ.2013.36.12.

Rossi, M., 2005. Deformation, transferts de matière et de fluide dans la croûte continentale : application aux massifs cristallins externes des Alpes. PhD Thesis. Université Joseph Fourier, p. 376.

Roujean, J.L., Leroy, M., Deschamps, P.Y., 1992. A bidirectional reflectance model of the Earth's surface for the correction of remote sensing data. J. Geophys. Res.: Atmosphere 97 (D18), 20455-20468.

Saito, T., Abe, M., Kunori, S., 1971. Study on weathering of granitic rocks (II). Butsuri- Tanko 24 (No. 5), 10-15.

Sgavetti, M., Pompilio, L., Meli, S., 2006. Reflectance spectroscopy $(0.3-2.5 \mu \mathrm{m})$ at various scales for bulk-rock identification. Geosphere 2 (3), $142-160$.

Shakesby, R.A., Matthews, J.A., Owen, G., 2006. The Schmidt hammer as a relative-age dating tool and its potential for calibrated-age dating in Holocene glaciated environments. Quat. Sci. Rev. 25 (21-22), 2846-2867.

Shields, J.A., Paul, E.A., St Arnaud, R.J., Head, W.K., 1968. Spectrophotometry measurement of soil color and its relationship to moisture and organic matter. Can. J. Soil Sci. 48 (3), 271-280.

Tomkins, M.D., Dortch, J.M., Hughes, P.D., 2016. Schmidt hammer exposure dating (SHED): establishment and implications for the retreat of the last British ice sheet. Quat. Geochronol. 33, 46-60. https://doi.org/10.1016/j.quageo.2016.02.002.

Tomkins, M.D., Huck, J.J., Dortch, J.M., Hughes, P.D., Kirbride, M.P., Barr, I.D., 2018a. Schmidt hammer exposure dating (SHED): calibration procedures, new exposure age data and an online calculator. Quat. Geochronol. 44, 55-62.

Tomkins, M.D., Dortch, J.M., Hughes, P.D., Huck, J.J., Stimson, A.G., Delmas, M., Calvet, M., Pallas, R., 2018b. Rapid age assessment of glacial landforms in the Pyrenees using Schmidt hammer exposure dating (SHED). Quat. Res. 90 (1), 26-37.

Torrent, J., Schwertmann, U., Fechter, H., Alferez, F., 1984. Quantitative relationship between soil colour and hematite content. Soil Sci. 136, 354-358.

Tucker, C., 1978. Red and Photographic Infrared Linear Combinations for Monitoring Vegetation. Technical Memorandum 79620. NASA.

Verhoeven, G., 2008. Imaging the invisible using modified digital still cameras for straightforward and low-cost archaeological near-infrared photography. J. Archaeol. Sci. 35, 3087-3100.

Vescovo, L., Wohlfahrt, G., Balzarolo, M., Pilloni, S., Sottocornola, M., Rodeghiero, M., Gianelle, D., 2012. New spectral vegetation indices based on the nearinfrared shoulder wavelengths for remote detection of grassland phytomass. Int. J. Rem. Sens.

33, 2178-2195. https://doi.org/10.1080/01431161.2011.607195.

Wang, X., Zeng, L., Wiens, M., Schlobmacher, U., Jochum, K.P., Schroder, H.C.," Müller, W.E., 2011. Evidence for a biogenic, microorganismal origin of rock varnish from the gangdese Belt of Tibet. Micron 52, 401-411.

Wold, S., Ruhe, A., Wold, H., Dunn III, W.J., 1984. The collinearity problem in linear regression. The partial least squares (PLS) approach to generalized inverses. SIAM J. Sci. Stat. Comput. 5, 735-743. https://doi.org/10.1137/0905052. 


\begin{tabular}{|c|c|c|c|c|c|c|c|c|c|c|c|c|}
\hline \multirow[t]{3}{*}{ Sample } & \multirow{3}{*}{$\begin{array}{l}\text { Elevation } \\
\text { (m a.s.l.) }\end{array}$} & \multirow{3}{*}{$\begin{array}{l}\text { Dip } \\
\text { direction } \\
\text { (') }\end{array}$} & \multirow{3}{*}{$\begin{array}{l}\text { Dip } \\
\text { (') }\end{array}$} & \multirow{3}{*}{$\begin{array}{l}\text { Exposure } \\
\text { age (ka) }\end{array}$} & \multirow{3}{*}{$\begin{array}{l}\text { Uncer- } \\
\text { tainty } \\
\text { (ka) }\end{array}$} & \multirow{3}{*}{$\begin{array}{l}\text { Exposure } \\
\text { age (log, ka) }\end{array}$} & \multirow{3}{*}{$\begin{array}{l}\text { Uncer- } \\
\text { tainty } \\
\text { (log, ka) }\end{array}$} & \multicolumn{4}{|c|}{ Reflectance value } & \multirow{3}{*}{$\begin{array}{l}\text { Green } \\
\text { Infrared Index } \\
\text { (GRIGR) }\end{array}$} \\
\hline & & & & & & & & Blue & Green & Red & Infrared & \\
\hline & & & & & & & & $(450 \mathrm{~nm})$ & $(530 \mathrm{~nm})$ & $(700 \mathrm{~nm})$ & $(770 \mathrm{~nm})$ & \\
\hline ADMf & 3800 & - & - & 0.00 & frech rock) & - & - & 0.272 & 0.298 & 0.304 & 0.307 & 0.014 \\
\hline ADMI & 3821 & 165 & 86 & 38.00 & 3.00 & 3.638 & 1.099 & 0.094 & 0.131 & 0.228 & 0.238 & 0.288 \\
\hline ADM2 & 3625 & 138 & 85 & 1.26 & 0.16 & 0.231 & -1.833 & 0.102 & 0.126 & 0.137 & 0.150 & 0.085 \\
\hline ADM4 & 3762 & 127 & 79 & 5.83 & 0.45 & 1.763 & -0.799 & 0.130 & 0.170 & 0.243 & 0.254 & 0.197 \\
\hline ADM5 & 3761 & 149 & 79 & 6.69 & 0.59 & 1.901 & -0.528 & 0.154 & 0.190 & 0.260 & 0.269 & 0.172 \\
\hline ADMB & 3810 & 270 & 36 & 0.28 & 0.05 & -1.273 & -2.996 & 0.279 & 0.334 & 0.362 & 0.366 & 0.046 \\
\hline ADM9 & 3790 & 155 & 67 & 12.00 & 1.00 & 2.485 & 0.000 & 0.128 & 0.176 & 0.290 & 0.295 & 0.253 \\
\hline ADM11 & 3760 & 160 & 75 & 0.43 & 0.10 & -0.844 & -2.303 & 0.257 & 0.322 & 0.366 & 0.367 & 0.066 \\
\hline ADM12 & 3750 & 150 & 50 & 0.47 & 0.07 & -0.755 & -2.659 & 0.280 & 0.340 & 0.385 & 0.391 & 0.069 \\
\hline ADR1 & 3516 & 120 & 80 & 2.68 & 0.27 & 0.986 & -1.309 & 0.125 & 0.166 & 0.235 & 0.234 & 0.171 \\
\hline ADR2 & 3433 & 120 & 60 & 1.82 & 0.73 & 0.599 & -0.315 & 0.268 & 0.325 & 0.377 & 0.375 & 0.072 \\
\hline ADR3 & 3420 & 130 & 80 & 0.04 & 0.01 & -3.219 & -4.605 & 0.268 & 0.327 & 0.362 & 0.355 & 0.041 \\
\hline ADR 4 & 3397 & 110 & 75 & 0.48 & 0.11 & -0.734 & -2.207 & 0.196 & 0.251 & 0.305 & 0.301 & 0.091 \\
\hline ADR5 & 3309 & 130 & 75 & $<0.23$ & 0.09 & $<1.470$ & -2.408 & 0.258 & 0.299 & 0.318 & 0.322 & 0.038 \\
\hline ADR6 & 3450 & 90 & 74 & 88.40 & 7.60 & 4.482 & 2.028 & 0.101 & 0.143 & 0.303 & 0.311 & 0.371 \\
\hline ADR8 & 3322 & 150 & 42 & 4.49 & 0.40 & 1.502 & -0.916 & 0.108 & 0.150 & 0.238 & 0.241 & 0.234 \\
\hline ADR9 & 3277 & 148 & 82 & 1.42 & 0.19 & 0.351 & -1.661 & 0.176 & 0.233 & 0.316 & 0.316 & 0.152 \\
\hline ADR10 & 3372 & 115 & 70 & 0.80 & 0.10 & -0.223 & -2.303 & 0.151 & 0.193 & 0.232 & 0.239 & 0.107 \\
\hline ADR11 & 3337 & 130 & 85 & 1.69 & 0.20 & 0.525 & -1.609 & 0.191 & 0.255 & 0.337 & 0.331 & 0.129 \\
\hline ADR12 & 3305 & 105 & 30 & 6.83 & 0.59 & 1.921 & -0.528 & 0.108 & 0.156 & 0.242 & 0.248 & 0.227 \\
\hline CHD1 & 3602 & 148 & 78 & 4.10 & 0.38 & 1.411 & -0.968 & 0.152 & 0.217 & 0.342 & 0.340 & 0.221 \\
\hline CHD2 & 3577 & 170 & 82 & 3.94 & 0.44 & 1.371 & -0.821 & 0.203 & 0.262 & 0.375 & 0.373 & 0.175 \\
\hline CHD3 & 3556 & 105 & 82 & 2.96 & 0.34 & 1.085 & -1.079 & 0.191 & 0.279 & 0.447 & 0.440 & 0.224 \\
\hline CHD4 & 3526 & 220 & 90 & 0.40 & 0.04 & -0.916 & -3.219 & 0.229 & 0.278 & 0.318 & 0.324 & 0.077 \\
\hline CHD5 & 3505 & 170 & 71 & 5.66 & 0.47 & 1.733 & -0.755 & 0.194 & 0.263 & 0.364 & 0.360 & 0.157 \\
\hline CHD6 & 3502 & 170 & 72 & 0.52 & 0.10 & -0.654 & -2.303 & 0.237 & 0.313 & 0.389 & 0.384 & 0.103 \\
\hline $\cos 1$ & 3593 & 125 & 63 & 0.03 & 0.02 & -3.507 & -3.912 & 0.180 & 0.230 & 0.255 & 0.264 & 0.070 \\
\hline $\mathrm{ECO} 2$ & 3598 & 140 & 83 & 0.22 & 0.04 & -1.514 & -3.219 & 0.193 & 0.253 & 0.330 & 0.340 & 0.148 \\
\hline $\mathrm{ECO} 3$ & 3627 & 132 & 69 & 4.96 & 0.61 & 1.601 & -0.494 & 0.173 & 0.232 & 0.333 & 0.333 & 0.178 \\
\hline $\mathrm{ECO} 4$ & 3675 & 150 & 81 & 6.76 & 0.52 & 1.911 & -0.654 & 0.181 & 0.250 & 0.373 & 0.373 & 0.197 \\
\hline $\mathrm{ECO} 5$ & 3645 & 135 & 75 & 0.91 & 0.12 & -0.094 & -2.120 & 0.182 & 0.254 & 0.344 & 0.344 & 0.150 \\
\hline $\mathrm{ECO} 9$ & 3754 & 175 & 68 & 6.09 & 0.50 & 1.807 & -0.693 & 0.141 & 0.195 & 0.324 & 0.327 & 0.251 \\
\hline ECO10 & 3752 & 140 & 78 & 8.88 & 0.82 & 2.184 & -0.198 & 0.177 & 0.239 & 0.399 & 0.399 & 0.251 \\
\hline LA1 & 3525 & 120 & 65 & 10.49 & 1.10 & 2.350 & 0.095 & 0.181 & 0.236 & 0.347 & 0.346 & 0.190 \\
\hline LA2 & 3426 & 90 & 85 & 0.25 & 0.05 & -1.386 & -2.996 & 0.334 & 0.379 & 0.401 & 0.397 & 0.024 \\
\hline LA4 & 3384 & 180 & 90 & 8.60 & 0.91 & 2.152 & -0.094 & 0.143 & 0.184 & 0.258 & 0.259 & 0.169 \\
\hline PYR2 & 3380 & 136 & 85 & 51.30 & 4.70 & 3.938 & 1.548 & 0.161 & 0.207 & 0.307 & 0.313 & 0.204 \\
\hline PYR3 & 3355 & 140 & 68 & 2.26 & 0.33 & 0.815 & -1.109 & 0.223 & 0.293 & 0.364 & 0.370 & 0.116 \\
\hline PYR4 & 3451 & 145 & 60 & 3.24 & 0.33 & 1.176 & -1.109 & 0.185 & 0.255 & 0.383 & 0.381 & 0.198 \\
\hline PYR6 & 3364 & 109 & 65 & 0.46 & 0.06 & -0.777 & -2.813 & 0.179 & 0.213 & 0.237 & 0.236 & 0.051 \\
\hline PYR7 & 3318 & 125 & 62 & 0.48 & 0.08 & -0.734 & -2.526 & 0.260 & 0.298 & 0.317 & 0.313 & 0.025 \\
\hline TRII & 3525 & 148 & 88 & 7.05 & 0.78 & 1.953 & -0.248 & 0.137 & 0.196 & 0.302 & 0.312 & 0.228 \\
\hline TRI4 & 3465 & 48 & 86 & 1.75 & 0.21 & 0.560 & -1.561 & 0.209 & 0.282 & 0.372 & 0.304 & 0.153 \\
\hline TRI5 & 3462 & 145 & 90 & 6.56 & 0.62 & 1.881 & -0.478 & 0.136 & 0.194 & 0.313 & 0.323 & 0.249 \\
\hline TRI6 & 3615 & 108 & 85 & 20.50 & 1.60 & 3.020 & 0.470 & 0.137 & 0.190 & 0.318 & 0.319 & 0.253 \\
\hline TRI7 & 3567 & 90 & 86 & 12.80 & 1.10 & 2.549 & 0.095 & 0.253 & 0.332 & 0.422 & 0.417 & 0.113 \\
\hline TRI8 & 3492 & 152 & 80 & 8.30 & 0.75 & 2.116 & -0.288 & 0.209 & 0.290 & 0.403 & 0.403 & 0.163 \\
\hline TRI9 & 3545 & 98 & 85 & 2.03 & 0.29 & 0.708 & -1.238 & 0.337 & 0.389 & 0.429 & 0.430 & 0.050 \\
\hline TRII0 & 3515 & 104 & 82 & 0.62 & 0.15 & -0.478 & -1.897 & 0.206 & 0.265 & 0.345 & 0.354 & 0.142 \\
\hline TRI11 & 3488 & 75 & 85 & 0.76 & 0.08 & -0.274 & -2.526 & 0.251 & 0.317 & 0.380 & 0.377 & 0.087 \\
\hline TRI12 & 3442 & 87 & 80 & 0.47 & 0.08 & -0.755 & -2.526 & 0.234 & 0.299 & 0.351 & 0.348 & 0.076 \\
\hline TRO1 & 3475 & 112 & 83 & 0.42 & 0.07 & -0.868 & -2.659 & 0.244 & 0.291 & 0.318 & 0.324 & 0.052 \\
\hline TRO2 & 3470 & 135 & 85 & 4.19 & 0.41 & 1.433 & -0.892 & 0.143 & 0.201 & 0.277 & 0.286 & 0.173 \\
\hline TRO4 & 3480 & 105 & 74 & 2.08 & 0.38 & 0.732 & -0.968 & 0.264 & 0.336 & 0.424 & 0.434 & 0.128 \\
\hline TRO5 & 3430 & 89 & 81 & 0.12 & 0.03 & -2.120 & -3.507 & 0.418 & 0.449 & 0.450 & 0.450 & 0.002 \\
\hline TRO6 & 3619 & 135 & 64 & 22.90 & 1.90 & 3.131 & 0.642 & 0.156 & 0.217 & 0.365 & 0.367 & 0.257 \\
\hline TRO7 & 3598 & 98 & 88 & 1.59 & 0.20 & 0.464 & -1.609 & 0.208 & 0.283 & 0.371 & 0.374 & 0.138 \\
\hline TROS & 3548 & 109 & 69 & 4.40 & 0.42 & 1.482 & -0.868 & 0.178 & 0.235 & 0.332 & 0.337 & 0.178 \\
\hline
\end{tabular}

Tab. 1. Exposure age and reflectance values of the four selected wavelengths for the 58 dated granite samples from Mont Blanc massif rock walls used for the colour-age relationship study. As colour changes in a non-linear way, surface exposure ages (ka) are converted to natural logarithm (log ka). ADM: Aiguille du Midi; ADR: pointe Adolphe Rey; CHD: Chandelle du Tacul; COS: lower Cosmiques ridge; ECO: Cosmiques spur; LA: pointe Lachenal; PYR: Pyramide du Tacul; TRI: Trident du Tacul; TRO: Tour Ronde E face.

Tab. 2. RIGRI dating of 7 samples for which TCN failed, and 2 samples for which TCN age is considered outlier.

\begin{tabular}{lllllr}
\hline Sample & $\begin{array}{l}\text { Green reflectance } \\
\text { value }(530 \mathrm{~nm})\end{array}$ & $\begin{array}{l}\text { Infrared } \\
\text { reflectance value } \\
(770 \mathrm{~nm})\end{array}$ & $\begin{array}{l}\text { Green } \\
\text { Infrared } \\
\text { Index } \\
\text { (GRIGRI) }\end{array}$ & $\begin{array}{l}\text { GRIGRI } \\
\text { age (log, ka) }\end{array}$ & $\begin{array}{l}\text { GRIGRI } \\
\text { age (ka) }\end{array}$ \\
\hline ADM6 & 0.167 & 0.291 & $\mathbf{0 . 2 7 1}$ & 2.82 & $\mathbf{1 6 . 8 0}$ \\
ADM7 & 0.194 & 0.346 & $\mathbf{0 . 2 8 1}$ & 2.99 & $\mathbf{1 9 . 8 9}$ \\
ADR7 & 0.248 & 0.353 & $\mathbf{0 . 1 7 4}$ & 1.19 & $\mathbf{3 . 3 0}$ \\
CHD7 & 0.277 & 0.313 & $\mathbf{0 . 0 6 2}$ & -0.70 & $\mathbf{0 . 5 0}$ \\
PYR1 & 0.267 & 0.305 & $\mathbf{0 . 0 6 6}$ & -0.62 & $\mathbf{0 . 5 4}$ \\
PYR5 & 0.443 & 0.493 & $\mathbf{0 . 0 5 3}$ & -0.84 & $\mathbf{0 . 4 3}$ \\
TRI3 & 0.287 & 0.312 & $\mathbf{0 . 0 4 3}$ & -1.01 & $\mathbf{0 . 3 6}$ \\
TR03 & 0.276 & 0.281 & $\mathbf{0 . 0 0 9}$ & -1.58 & $\mathbf{0 . 2 1}$ \\
TR09 & 0.351 & 0.361 & $\mathbf{0 . 0 1 5}$ & -1.48 & $\mathbf{0 . 2 3}$ \\
\hline
\end{tabular}




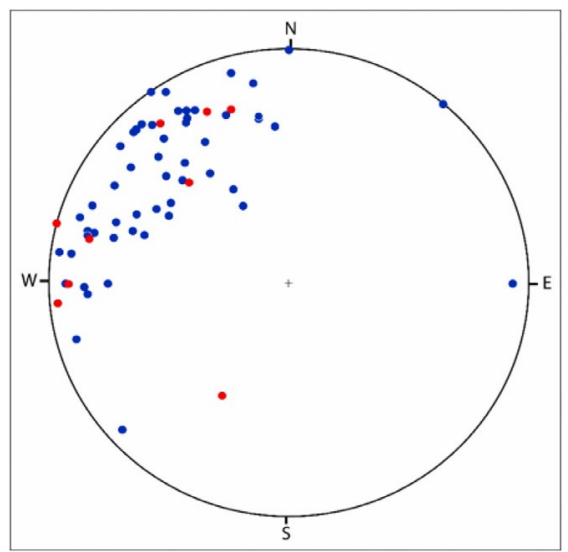

Fig. 1. Pole projection of strike and dip for all the sampling surfaces (Wulf stereonet). Blue: samples used for the GRIGRI analysis; red: samples with no TCN age.
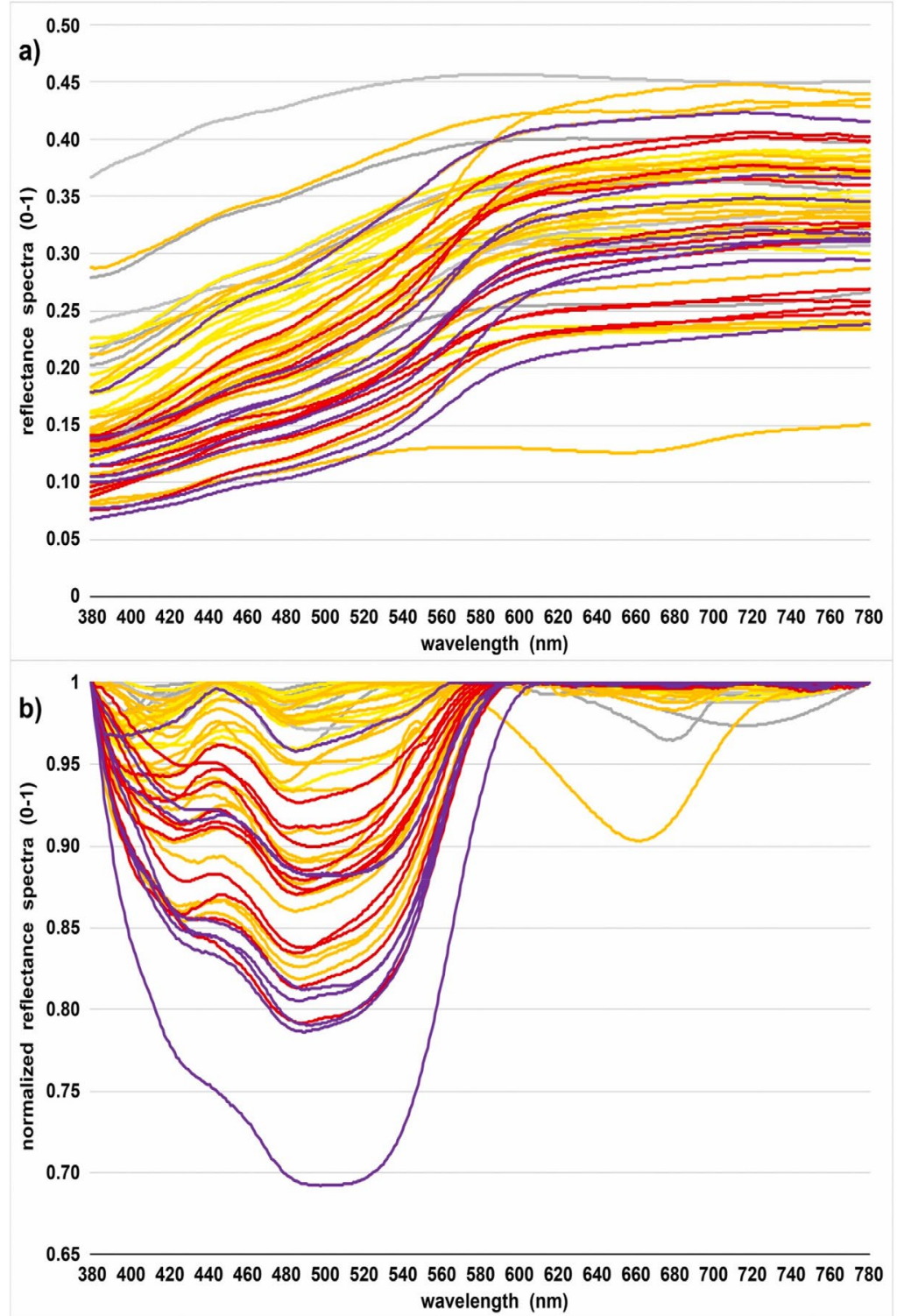

Fig. 2. Measured reflectance spectra and continuum-removed (normalized) spectra of the 58 dated granite samples from the Mont Blanc massif rock walls. Colours are according to sample exposure ages, with grey: $<0.3$ ka; yellow: 0.3-1 ka; orange: 1-5 ka; red: 5-10 ka; and purple: >10 ka. 


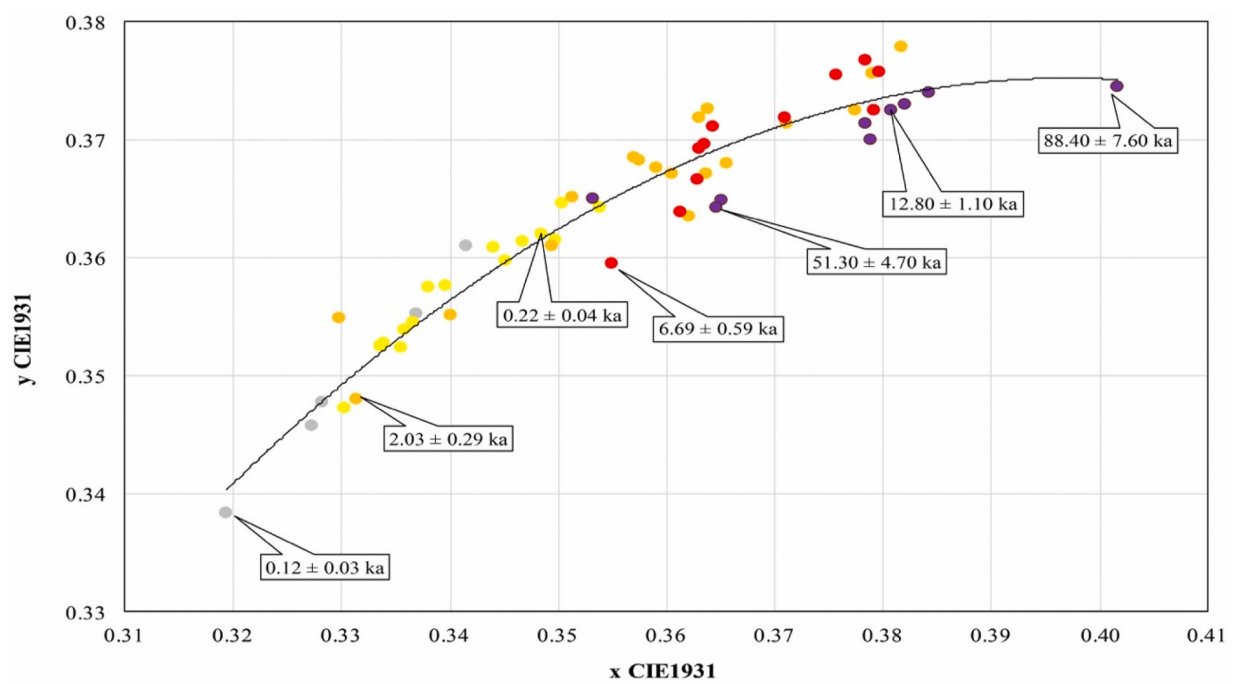

Fig. 3. Diagram of the CIE 1931 x,y values of the 59 granite samples from the Mont Blanc massif rock walls, with seven representative TCN surface exposure ages. Colours are according to sample exposure ages with same significance as in Fig. 2.

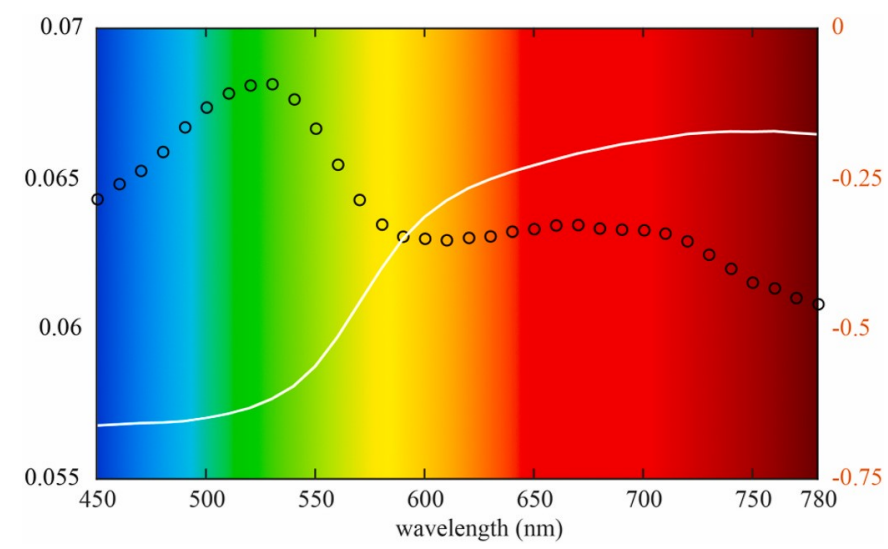

Fig. 4. Left axis (black circles): standard deviation every $10 \mathrm{~nm}$ in the final dataset spectra. Right axis (white line): correlation with the target log age. Background colours represent the theoretical colour of the corresponding wavelengths.

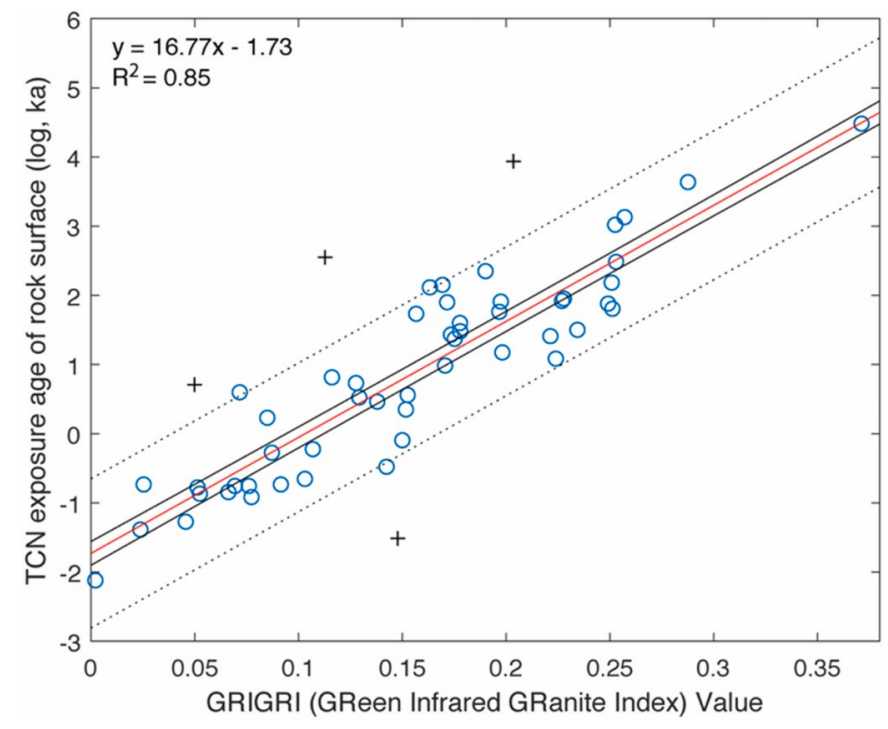

$\sigma$ uncertainty; dashed black lines represent confidence interval $(p<0.05)$. Crosses: four samples (ECO2, PYR2, TRI7, TRI9) excluded from the calculation because they were considered to be outliers according to their Cook's distance; they were included in the figure only for visualisation purposes. 


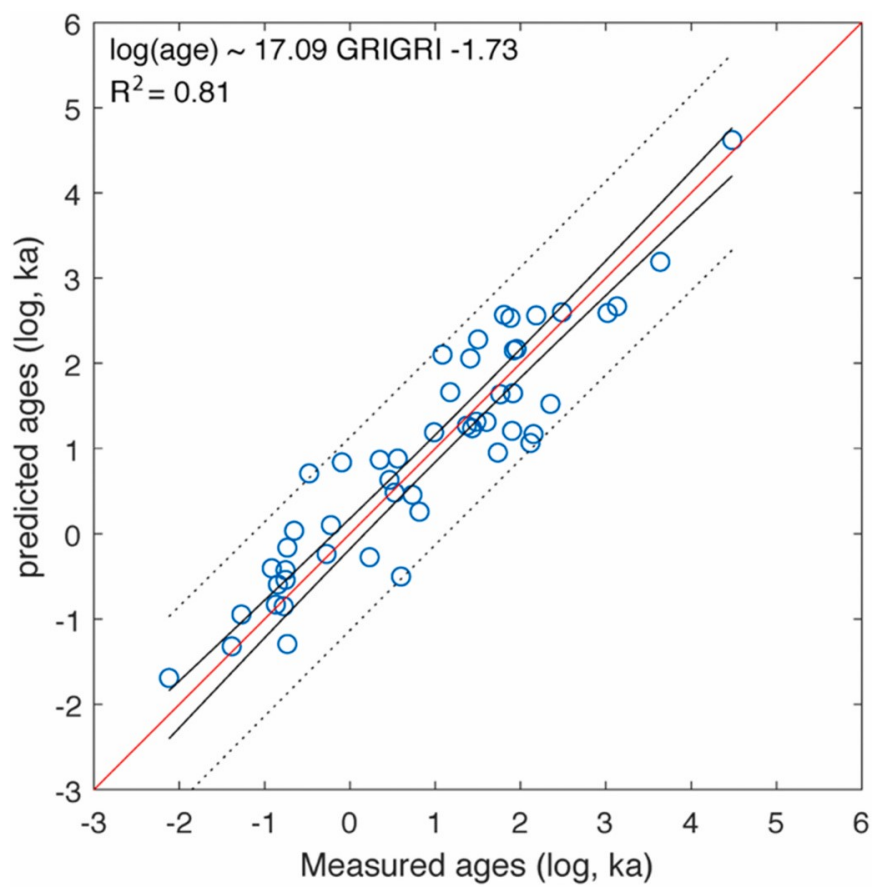

confidence interval $(\mathrm{P}<0.05)$.
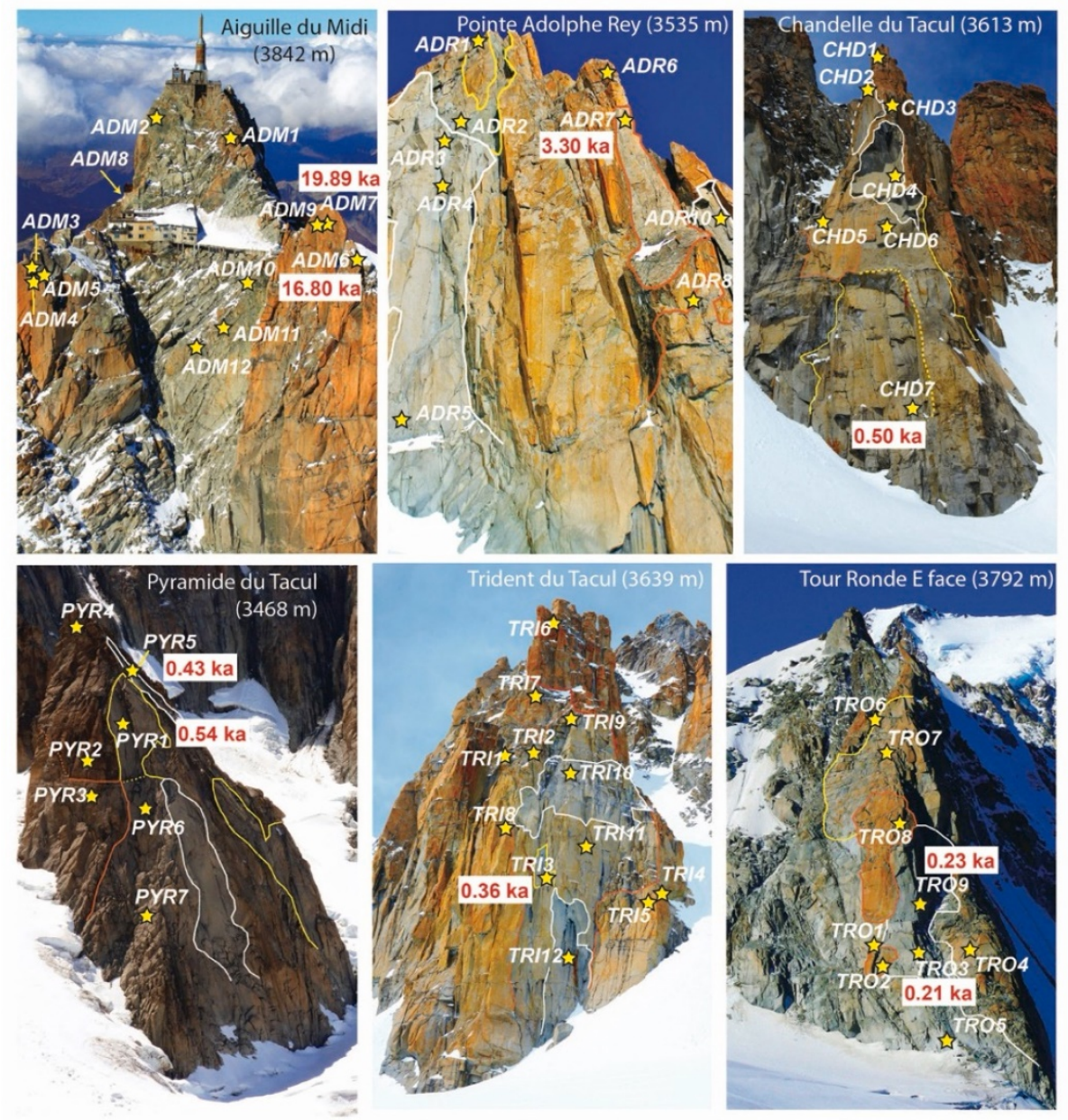